\title{
Betsy Nabel: never found a glass ceiling she couldn't break
}

$A_{t}$ t the beginning of this year, Elizabeth G. Nabel (Figure 1), formerly director of the National Heart, Lung, and Blood Institute (NHLBI), assumed the reins as president of the Brigham and Women's Hospital (BWH). The JCI recently had the chance to ask Nabel several questions about her move.

JCI: What motivated you to move to the BWH?

Nabel: It was a great honor to serve at the NIH for 10 years, including 5 years as Scientific Director of Clinical Research and then 5 years as Director of the NHLBI. My goal was always to return to an academic medical center in a leadership role. When the opportunity arose to return to BWH, where my husband and I trained and met, it was a dream come true.

JCI: Does your family plan to relocate entirely to Boston? Or is your husband [Gary Nabel, director of the Vaccine Research Center of the NIH] staying in Bethesda?

Nabel: Gary plans to continue his leadership role and scientific research at the VRC for the short term, as a number of exciting research discoveries are unfolding. Our 3 children are now in college and medical school.

JCI: Are you going to maintain a research laboratory?

Nabel: I have been fortunate to have had a successful research career over a number of years. The thrill of discovery still brings me great joy. I have been privileged to work with many talented investigators in basic and translational research. Those rewards still continue as I shape research activities at BWH. Unfortunately, there are only 24 hours in a day, and so, I need to be realistic about my time commitments. As a result, I'll be winding down my NIH lab over the remainder of the calendar year, but I plan to retain research collaborations with investigators at Harvard.

JCI: What do you anticipate will be your biggest challenge as president?

Nabel: We will explore our care delivery models and our cost structures. It appears we will transition from unfettered "fee-forservice" to a "bundled" or "global" payment system. As we redesign care, we must not lose sight of what is best for our patients as we continue to support the research and education branches of our mission.

JCI: Do you anticipate the economic situ-

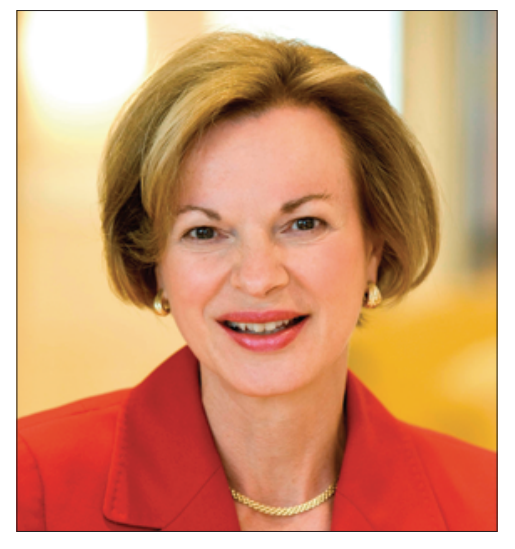

Figure 1

Betsy Nabel is back at BWH.

ation in the US and the new health care reforms will impact your plans for BWH?

Nabel: Massachusetts has had expanded health coverage for 4 years now under state legislation, often referred to as the Massachusetts Mandate, and so the state is about 3-5 years ahead of the country in terms of implementing health care reform. Approximately $97 \%$ of Massachusetts residents now have health care coverage. The focus is now on health care costs, and Partners HealthCare (the not-for-profit organization founded by BWH and the Massachusetts General Hospital in 1994) is working hard to find effective solutions.

JCI: At the NIH, you had to address issues of conflict of interest in an environment with strict oversight and regulations, especially related to involvement with the private sector. Academic institutions, in particular Harvard, have recently tightened restrictions on senior leadership with regard to potential conflict of interest. What is your opinion about the right balance of partnership between industry and academia and the role that academic leaders should play in this process?

Nabel: Partnerships between industry and academia are critical to the success of translating basic discoveries to improve care of patients and hence must be encouraged. Conflicts of interest are likely to arise and should be managed in an appropriate and responsible manner. The key is disclosure and transparency. Academic leaders must guide those partnerships in a thoughtful manner and should serve as role models. I applaud Partners HealthCare for the leadership role our organization has taken in this area.

JCI: As a woman who has spent many years as a successful physician-scientist, what do you think are the greatest challenges facing women in academic medicine?

Nabel: The opportunities and challenges facing women and men physician-scientists are overlapping, yet distinct. Common to both, we all seek to make discoveries that will advance scientific knowledge, contribute to patient treatments, and impact human health. Yet, women face unique challenges with respect to child bearing and child rearing, as we typically assume the majority of responsibilities for raising a family. The second set of challenges for women is movement up the promotions ladder and into leadership roles. A glass ceiling still exists at many institutions. I firmly believe that my job is to foster an environment where women's careers can flourish in the context of their family responsibilities. This requires institutional commitment, flexibility, and creativity in the appointment and promotions process (including tenure clocks), in mentoring career development, and in structuring faculty positions and salaries. Put simply, we can't afford to lose the wealth of talent women bring to the multifaceted roles within academic medical centers.

JCI: What advice do you have for those just beginning their careers?

Nabel: Find what you enjoy doing and pursue it with focus, discipline, and vigor. Be mindful of the matrix organization in which you work (research lab, department, hospital, professional organizations, etc.), network, and establish constructive collaborations. Seek out mentors, besides your research PI, who can provide objective, supportive, and mature advice about your career development. Establish a positive, respectful relationship with your boss. Articulate career goals and on a yearly basis review your goals and progress toward them with your boss and mentors. Don't lose sight of your family. And, importantly, have fun and enjoy the ride!

\section{Ushma S. Neill}

